\title{
Bernoulli in the Operating Room: From the Perspective of a Cardiac Surgeon
}

\author{
Peter Matt $^{1}$ \\ ${ }^{1}$ Division of Cardiac Surgery, University Hospital Basel, Basel, \\ Switzerland \\ Thorac Cardiovasc Surg 2014;62:656-661.
}

\begin{abstract}
Address for correspondence Peter Matt, MD, PD, Division of Cardiac Surgery, University Hospital Basel, Spitalstrasse 21, Basel 4031, Switzerland (e-mail: peter.matt@usb.ch).
\end{abstract}

\begin{abstract}
Keywords

- history

- heart valve surgery

- cardiopulmonary bypass

The Bernoullis were one of the most distinguished families in the history of science. It was Daniel Bernoulli who applied mathematical physics to medicine to further his understanding of physiological mechanisms that have an impact even in today's highend medicine. His masterwork was the analysis of fluid dynamics, which resulted in Bernoulli's law. Most important for cardiac surgery, it describes how a centrifugal pump works within an extracorporeal circulation, lays the basis for measuring a gradient over a stenotic heart valve, and explains how to measure the transit time flow within a bypass graft.
\end{abstract}

\section{Introduction}

From the 17th century onwards, the Bernoullis were one of the most distinguished families in the history of science. ${ }^{1}$ Their scientific accomplishments, mainly in mathematics and physics at the University Basel, Switzerland, are outstanding. In particular those of Daniel Bernoulli, who applied mathematical physics to medicine to further his understanding and to explain a variety of physiological mechanisms, had and have a significant impact in daily clinical practice. This is true even in today's high-end medicine field of cardiac surgery.

\section{The Bernoulli Family}

The scientific record of the Bernoulli family in Basel starts with Jakob Bernoulli (1654-1705). 2,3 He was appointed professor of mathematics in Basel in 1687 and was one of the first mathematicians to work on the calculus of variations and mathematical probability. Johann Bernoulli (1667-1748), the younger brother of Jakob, was required to study medicine, but he was more interested in mathematics and physics. ${ }^{2,3} \mathrm{He}$ became a brilliant scientist and was one of the most famous mathematicians of his time, after Newton and Leibniz. His three sons, Nicolaus (1695-1726), Daniel (1700-1782), and Johann II (1710-1790), were also scientists. ${ }^{2,3}$ Of the three,
Daniel Bernoulli was the most famous with achievements not only in mathematics and physics but also in a variety of natural sciences including medicine.

\section{Daniel Bernoulli, Scientist}

\section{First Scientific Works}

At a young age, Daniel Bernoulli already showed interest in mathematics and physics. ${ }^{1-3}$ However, his father tried to force him into a career as a merchant. Daniel strongly opposed this, but then agreed to study medicine at the University Basel, then Heidelberg, Germany, and Strasbourg, France. Meanwhile, Johann continued teaching Daniel mathematics and physics. Among the many topics they discussed, one was to have a substantial influence on Daniel's future discoveries. It was the "Law of Vis Viva Conservation," known today as the "Law of Conservation of Energy."1 What Daniel learned about the conservation of energy he applied in medicine to solve physiological questions. Thus, in his doctoral dissertation, he explained part of the mechanics of breathing with the help of geometric constructions and appropriate calculations. In 1721, aged 21, he published his results in a book entitled "De Respiratione"1,4:

... as the shape formed by the ribs corresponds to an ellipse and the ribs, when stacked one above the other, form an received

August 5, 2013

accepted after revision

December 19, 2013

published online

May 1, 2014 (c) 2014 Georg Thieme Verlag KG Stuttgart · New York
DOI http://dx.doi.org/ 10.1055/s-0034-1370764. ISSN 0171-6425. 
elliptical cylinder, one can use the basic elements of geometry to demonstrate that the cylinder formed when the ribs have risen has a greater volume than that which is formed by the ribs in their lowered position. The diaphragm, after expiration, is convex to the lobes of the lungs and has the function of making the chest space smaller or larger, sinking with inspiration and rising with expiration aided by the diaphragmatic muscles...

Daniel Bernoulli also showed a strong interest in fluid dynamics, and in this context he was especially attracted to the scientific work of the English physician William Harvey. ${ }^{1}$ In the 17th century, in his book "De Motu Cordis" Harvey was the first to describe the human blood circulation and the heart as a pump forcing the blood to flow like a fluid within the body. ${ }^{5}$
Daniel wanted to follow an academic career after his dissertation, like his father, and applied for two chairs at the University Basel. Those were then decided by drawing lots, but Daniel had no luck. As a consequence, he left Basel for Venice to study practical medicine with Michelotti, one of the most respected physicians of the time, who also studied the blood flow within the body. ${ }^{1}$ Additionally, Daniel worked on mathematics and physics and published his results in the book "Exercitationes Quaedam Mathematicae"6 in 1724. This was a work of four parts, of which the second concerns the flow of water from a hole into a container including a discussion of Newton's theories and corresponding to his medical work on the flow of blood and blood pressure. ${ }^{1}$ This publication launched Daniel's scientific career and made him famous across Europe, more in mathematics than in medicine.

\section{DANIELIS BERNOULL』 Joß Fin,} Med. Prof, Basil,

$\triangle C A D$. SCIENT. IMPER. PETROPOLITANE, PRIUS MATHESEOS: SUBLIMIORIS PROF.ORD. NUNC MEMBRI ET PROF.HONOR. HYDRODYNAMICA, DE VIRIBUS ET MOTIBUS FLUIDORUM COMMENT ARII. OPUS ACADEMICUM AB AUCTORE, DUM PETROPOLI AGERET.

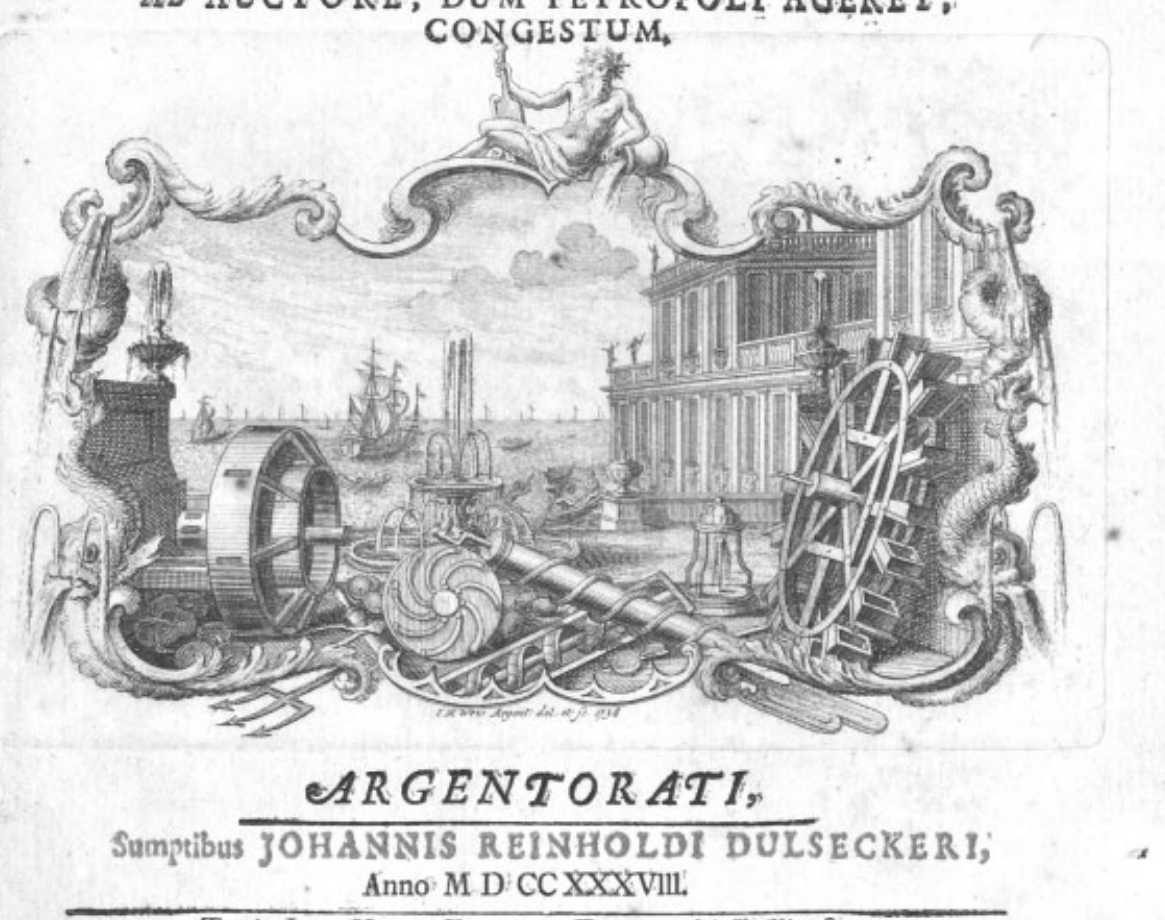

Typis Joh. Henr. Decker, Typographi Bafilienfis,

Fig. 1 Title page of the book "Hydrodynamica." 


\section{Master Work: Hydrodynamics}

In 1725, Daniel Bernoulli, together with his older brother Nicolaus, was offered a chair of mathematics at the newly founded "Imperial Academy" at St. Petersburg, Russia. ${ }^{1-3}$ Less than a year after they arrived there, Nicolaus died, aged 31, as a result of an intestinal infection. Daniel thought of returning to Basel, but his father arranged for another promising student from Basel, Leonard Euler, to go to St. Petersburg to work with Daniel. Euler arrived in 1727 and the subsequent period in St. Petersburg was a productive time for both.

Daniel continued his studies on the flow of fluids in tubes producing, for the first time, the correct analysis of water flowing from a hole into a container. ${ }^{1}$ In addition, he revealed the relationship between the velocity at which blood flows and its pressure. Daniel experimented by puncturing the wall of a pipe with a small open-ended straw and found that the height to which the fluid rose was related to the fluid pressure at this point. The explanation for this effect was based on the principle of conservation of energy, which he had studied with his father long before. Bernoulli, with Euler's help, proved mathematically what he had observed physically. Soon physicians all over Europe were measuring patients' blood pressure by sticking point-ended glass tubes directly into their arteries. ${ }^{2,3}$ Taking his discoveries further, Bernoulli realized that just as a moving body exchanges its kinetic energy for potential energy when it gains height, a moving fluid exchanges its kinetic energy for pressure. This was the background of Bernoulli's law, now known as Bernoulli fluid pressure equation ${ }^{7}$ :

$$
p+1 / 2 \rho v^{2}+\rho g h=\text { constant }
$$

where $p$ is the pressure, $\rho$ (rho) is the density of the fluid, $v$ is its velocity, $g$ is the acceleration due to gravity, and $h$ is the height. It follows from this law that the pressure falls if the velocity of the fluid increases.

Daniel completed his works on the flow of fluids in the book "Hydrodynamica" while he was still in St. Petersburg but published the book later in 1738 ( - Fig. 1). ${ }^{8}$ This was his most important and famous publication, and even the term "hydrodynamic" was first used by him.

\section{Calculation of the Heart's Work}

Daniel Bernoulli left St. Petersburg in 1733 and returned to Basel where he took the chair in anatomy and botany at the University Basel. ${ }^{1,2}$ His lectures focused particularly on the anatomy and the mechanical power of the heart. He used for the first time the term "work" done by the heart and presented a method of calculating it. He defined the work as "weight times lifting height" and used for his calculation a stroke volume of $62 \mathrm{~g}$ (2 ounces), a value based on the work of Harvey, and blood pressure. ${ }^{1}$ While Daniel assessed the stroke volume correctly, the blood pressure he used was much too low leading to an overestimate of the work done by the heart. In a prize-winning paper presented to the Paris Académie des Sciences in 1753 , he stated ${ }^{9}$ :

... only the heart's work can be determined with reasonable accuracy; for it is known that it beats $\sim 115200$ times in a day and that it pushes approximately two ounces of blood with each systole, and observations and experiments seem to prove that the blood is ejected from the heart with a velocity that would allow it to reach a height of approximately eight feet; this is the performance of the left ventricle, and that of the right ventricle will make about a quarter of this. Thus one can estimate the heart's daily work equal to that of elevating 144000 pounds to the height of one foot [around $24000 \mathrm{~m}-\mathrm{kg}$ ]...

Daniel's concept of calculating the work of the heart was correct, but it took over 100 years until physiology understood and accepted his analysis leading to the values accepted today $(19,200-20,000 \mathrm{~m} \mathrm{~kg})^{1}$

\section{Bernoulli in the Operating Room}

\section{The Centrifugal Pump}

Coronary artery bypass surgery (CABG) is the most common procedure in cardiac surgery. At present, CABG with the use of cardiopulmonary bypass through a full sternotomy is the standard surgical technique in most centers. While off-pump coronary artery bypass grafting has become a promising alternative to conventional bypass surgery, some patients may still require extracorporeal support. Concepts of extracorporeal circulation using closed circuits with low-priming volume and less inflammatory response were developed to meet the requirements of a minimized extracorporeal circuit (MECC). ${ }^{10}$ The pump to maintain the blood flow and pressure within the MECC is a centrifugal pump ( - Fig. 2), and the basic principle of the pump is based on the Bernoulli law. ${ }^{11}$

A centrifugal pump is essentially a velocity machine. ${ }^{11}$ It works by energy transfer of a pivoting impeller to a fluid within an external housing. The fluid reaches its maximum velocity as it reaches the pump impeller's outer diameter. At this point, all of the increased velocity energy available from the rotating impeller has been imparted to the fluid. When the fluid passes from the relatively confined smaller space inside the pump with a relatively high velocity to an outer region of increased area, its velocity decreases. As the fluid exits the pump impeller into the lower velocity zone, there is little or no change in its static elevation difference. Therefore, based on the Bernoulli law, and to maintain conservation of energy with the reduced velocity head on exiting the pump, and the potential static head relatively unchanged, then the only other energy component is the pressure component. ${ }^{11}$ At this point in the pumping system, the velocity head energy is transformed into pressure head energy, which maintains the patient's blood pressure during CABG.

\section{Transit Time Flow Measurement of the Bypass Graft}

The quality of surgical anastomoses in CABG is crucial to avoid early and late graft failure. For optimal operative results, good and reliable methods for assessment of the technical quality of the created bypasses are needed. ${ }^{12}$ At present, transit time flow measurement (TTFM) is the most common intraoperative method for assessment of the function of the graft. TTFM is convenient and assessment of the absolute graft flow, 


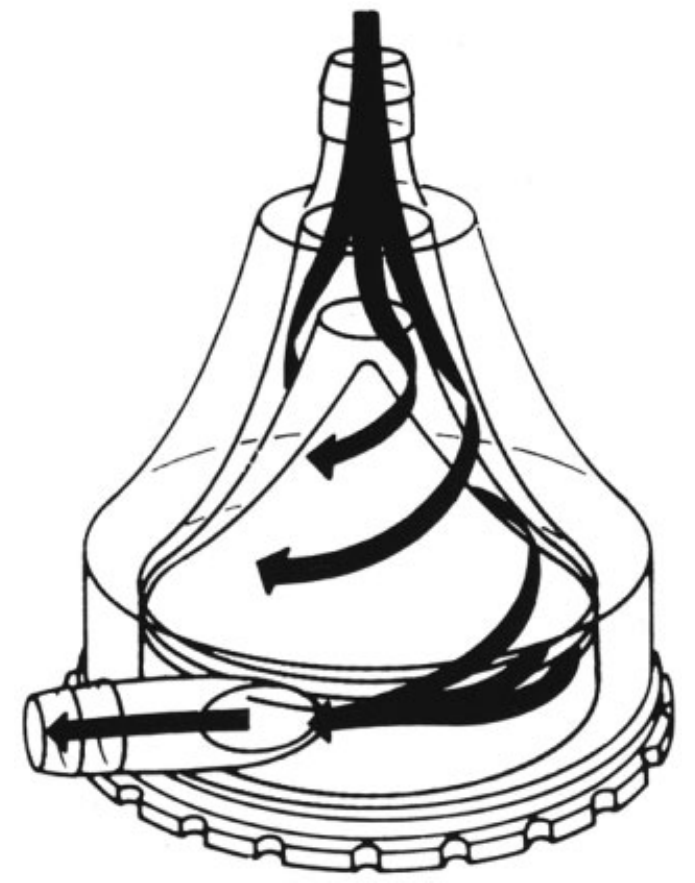

Fig. 2 Principle of a centrifugal pump; arrows demonstrate the fluid flow driven by the impeller.

related to graft type, vessel size, degree of stenosis, quality of anastomosis, and outflow area, can predict technically inadequate grafts, mandating graft revision. The method used to measure the flow within the grafts is based in part on the work of Bernoulli as the blood flow within a "tube" is assessed. The TTFM probe has a defined size and is laid around the graft (-Fig. $\mathbf{3}$ ), the blood flow velocity is measured using the Doppler principle, and, as a result, the volume flow through the graft can be calculated throughout the cardiac cycle. $^{12}$

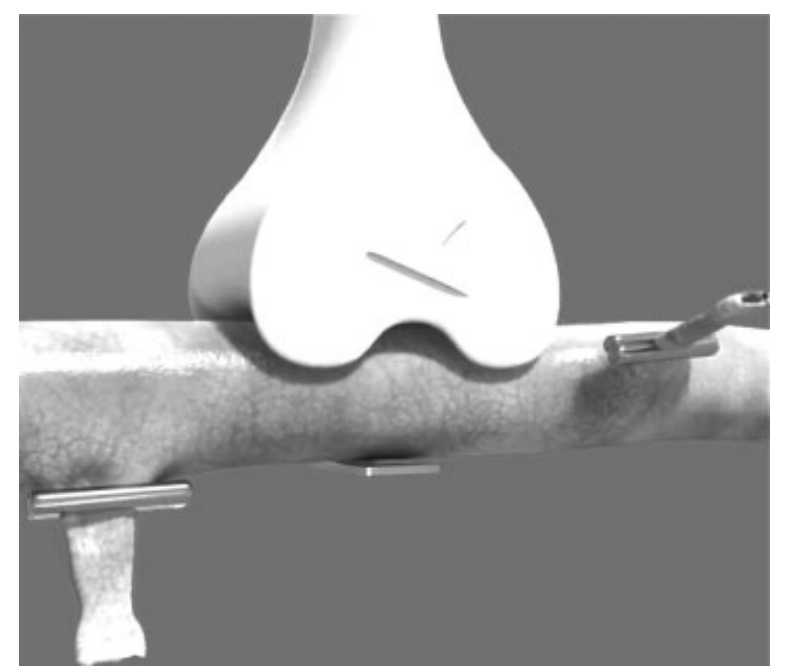

Fig. 3 Transit time flow measurement probe laid around the coronary bypass graft.

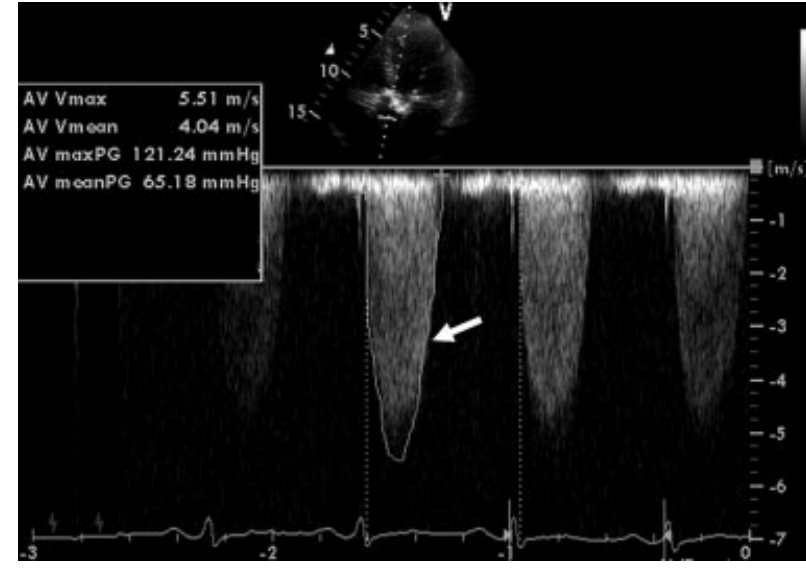

Fig. 4 Transthoracic echocardiography with Doppler examination showing the blood flow velocity at the aortic valve during the cardiac cycle: the white arrow marks the velocity curve; the box on the left shows the measured and calculated values. AV Vmax, maximum flow velocity at the aortic valve; $A \bigvee \vee m e a n$, mean flow velocity at the aortic valve; $A V$ maxPG, maximum peak gradient at the aortic valve; $A V$ meanPG, mean peak gradient at the aortic valve.

\section{Heart Valve Surgery}

Aortic valve stenosis is the most common valve disease, and aortic valve replacement is the second most common procedure in cardiac surgery. Patients with severe aortic stenosis should be promptly referred for surgical valve replacement, as survival is poor unless outflow obstruction is relieved. ${ }^{13}$ The severity of a stenosis is mainly defined through the increased pressure gradient over the diseased valve, and to measure this gradient the "Bernoulli fluid pressure equation" as mentioned above is used. This equation can be transformed and, through insertion of the density of blood, be rewritten as what is now called the "modified Bernoulli equation"13,14:

$$
\Delta p \approx 4 v^{2}(\mathrm{~mm} \mathrm{Hg})
$$

where $\Delta p$ represents the pressure gradient over the stenotic aortic valve, and this is only a function of the blood velocity $(v)$ at the aortic valve. The velocity in this area can easily be measured using transthoracic echocardiography and the Doppler effect (-Fig. 4).

Other parameters help in assessing the severity of the valve defect, for example, the aortic valve orifice area, the maximal velocity across the valve, and others, but the mean and peak gradients over the valve calculated using the "modified Bernoulli equation" remain important parameters in evaluating the degree of aortic valve stenosis. ${ }^{13,15}$

\section{Surgical Technique of Valve Implantation}

The Bernoulli equation is important in determining the surgical technique used to implant a valve prosthesis. The aim is to implant the prosthesis with a minimal valve gradient. ${ }^{15} \mathrm{~A}$ low gradient over the prosthesis maximizes the relief of pressure on the myocardium and subsequently results in fast recovery and remodeling of the heart which subsequently 
leads to improved mid- and long-term survival. ${ }^{15}$ The prosthesis gradient is measured with echocardiography, again using the "modified Bernoulli equation."14 A minimal prosthesis gradient is achieved through complete resection of the calcified aortic leaflets and supra-annular implantation of a large prosthesis with a maximum valve opening. ${ }^{16}$ Of course, the gradient over the implanted valve depends not only on the surgical technique but also on the type of implanted prosthesis. $^{17}$

In addition to those described above, the Bernoulli law explains many other phenomena both inside and outside medicine. It largely explains why an airplane wing gives lift to the plane, why the atmospheric pressure inside a hurricane is low, and why the roofs of houses are often simply lifted off during a hurricane; it describes the flight path of a ball with spin (e.g., soccer, tennis, and golf), the mechanism of a jet ski, and many other phenomena. ${ }^{1-3,7,18}$

\section{Limitations of the Bernoulli Equation}

The principle of conservation of energy used by the Bernoulli equation is a basic concept in physics that describes hydrodynamic problems. It is important to realize that in the derivation of the Bernoulli equation, several assumptions were made that simplify reality. It also assumes steady, laminar flow as well as an incompressible fluid. The situation for the heart and the circulatory system is more complex with its pulsatile flow conditions, turbulence, and other frictional effects. Furthermore, blood is a so-called non-Newtonian fluid, that is, it has viscoelastic properties that give it a type of memory. Accordingly, the situation in rotary blood pumps is more complex in reality and cannot be adequately described only by the principle of conservation of energy of a fluid. In modern medicine, computational fluid dynamics models based on the full equations and taking into account all the above-mentioned effects are employed to study this complex system. Nevertheless, the Bernoulli equation is a physical concept that sets the basis for understanding the mechanisms of blood flow and basic hydrodynamic problems and it has been of great historical significance to cardiac medicine.

\section{Daniel Bernoulli's Later Works}

In 1750, Daniel Bernoulli was appointed Chair of Physics at the University Basel and taught physics until $1776 .^{1-3} \mathrm{He}$ maintained his Chair in the medical faculty and became their Dean seven times. Daniel produced further excellent scientific work during his years in Basel, not just in physics and mathematics or medicine. Most impressive is his active and imaginative mind, which got to grips with the most varied scientific areas. In 1760, for example, Bernoulli presented a paper, using probability, to the Paris Académie on the revolutionary concept of inoculating a population against smallpox. $^{2}$ Bernoulli calculated that at that time, roughly threequarters of the population of Europe had been infected with smallpox, and one-tenth of all deaths were due to smallpox. He reported that anyone who had survived smallpox had an immunity to the disease, and based on his statistics he recommended a process called variolation, deliberately inducing what was then called "artificial smallpox" in people so that they suffered a milder infection that would later protect them from serious disease. Although this procedure carried a slight risk of dying, at least according to the statistical work of Daniel Bernoulli, using this approach, smallpox epidemics ceased to be a problem at least in England, by the end of the 19 th century.

Another important aspect of Daniel Bernoulli's work during his time in Basel that proved important in the development of mathematical physics was his acceptance of many of Newton's theories and his use of those together with the tools coming from the more powerful calculus of Leibniz. ${ }^{1,3}$ Daniel worked in Basel on mechanics and again used the principle of conservation of energy, which supported Newton's basic equations.

In 1782, Daniel Bernoulli died, at the age of 82 years, in Basel. ${ }^{1}$ Daniel together with his father, Johann, his uncle, Jakob, and their close friend Leonard Euler were among the most outstanding scientists and mathematicians in Europe in the 17th and 18th centuries. Their achievements still influence our daily lives and practices, even in the operating room. What heroes!

\section{Acknowledgments}

The author would like to thank H. Matt, K. Matt, and S. Matt, $\mathrm{PhD}$, for their wonderful help and discussion in setting up this manuscript, and F. Eckstein, MD, M. Heberer, MD, and M. Gray for their professional editing.

\section{Disclosure \\ None.}

\section{References}

1 Speiser D. Die Werke von Daniel Bernoulli. Band 1. Basel, Switzerland: Birkhäuser Verlag; 1996

2 Tent MBW. Leonard Euler and the Bernoullis: Mathematicians from Basel. MA, USA: AK Peters Ltd.; 2009

3 Nagel F, Verdun A. Geschickte Leute, die was praestiren können. Herzogenrath, Germany: Shaker Verlag; 2005

4 Bernoulli D. Dissertatio Inauguralis Physico-Medica De Respiratione. University of Basel; 1721

5 Harvey W. Exercitatio Anatomica de Motu Cordis et Sanguinis in Animalibus. Francofurti; 1628

6 Bernoulli D. Exercitationes Quaedam Mathematicae. Venetiis; 1724

7 Darrigol O. Worlds of Flow. Oxford: Oxford University Press; 2005

8 Bernoulli D. Hydrodynamica, sive De Viribus et Motibus Fluidorum Commentarii. Basiliensis; 1738

9 Bernoulli D. Recherches sur la Maniere la plus Avantageuse de Suppléer à l'action du Vent sur les Grand Vaisseaux. Paris: Prix; 1753:3-99

10 Immer FF, Ackermann A, Gygax E, et al. Minimal extracorporeal circulation is a promising technique for coronary artery bypass grafting. Ann Thorac Surg 2007;84(5):1515-1520, discussion 1521 
11 Pagani FD. Continuous-flow rotary left ventricular assist devices with “3rd generation" design. Semin Thorac Cardiovasc Surg 2008; 20(3):255-263

12 Jokinen JJ, Werkkala K, Vainikka T, Peräkylä T, Simpanen J, Ihlberg L. Clinical value of intra-operative transit-time flow measurement for coronary artery bypass grafting: a prospective angiographycontrolled study. Eur J Cardiothorac Surg 2011;39(6):918-923

13 Bonow: Braunwald's Heart Disease-A Textbook of Cardiovascular Medicine. 9th ed. Philadelphia, PA: W. B. Elsevier Saunders; 2011

14 Shapiro LM, Kenny A. Echokardiographie. Berne, Switzerland: Hans Huber Verlag; 2002
15 Kirklin/Barratt-Boyes Cardiac Surgery. 4th ed. Philadelphia, PA: W.B. Elsevier Saunders; 2013

16 Doenst T, Amorim PA, Al-Alam N, Lehmann S, Mukherjee C, Faerber G. Where is the common sense in aortic valve replacement? A review of hemodynamics and sizing of stented tissue valves. J Thorac Cardiovasc Surg 2011;142(5): $1180-1187$

17 Yoganathan AP, He Z, Casey Jones S. Fluid mechanics of heart valves. Annu Rev Biomed Eng 2004;6:331-362

18 Williams K. Two Cultures. Essays in Honour of David Speiser. Basel, Switzerland: Birkhäuser Verlag; 2000 